\title{
ESTUDO DE CASO: FISSURAS EM LAJE DE EDIFÍCIO RESIDENCIAL EM BELO HORIZONTE
}

\author{
BRASILEIRO, MELINA BARROS \\ Mestranda em Engenharia Civil \\ Universidade Federal de Ouro Preto \\ Minas Gerais; Brasil \\ melbrasileiro@hotmail.com \\ FIGUEIREDO, ALINE SANTANA \\ Mestranda em Engenharia Civil \\ Universidade Federal de Ouro Preto \\ Minas Gerais; Brasil \\ alinesantanafigueiredo@gmail.com
}

\author{
Engenheiro Civil, D. Sc. \\ Universidade Federal de Ouro Preto \\ Minas Gerais; Brasil \\ guilhermebrigolini@ufop.edu.br
}

SILVA, GUILHERME JORGE BRIGOLINI

\author{
CAETANO, MARINA ALTOÉ \\ Mestranda em Engenharia Civil \\ Universidade Federal de Ouro Preto \\ Minas Gerais; Brasil \\ altoemarina@gmail.com
}

\author{
MATIAS, ANA CAROLINA PAULA \\ Mestranda em Engenharia Civil \\ Universidade Federal de Ouro Preto \\ Minas Gerais; Brasil \\ ana.carolina.p.matias@gmail.com
}

\author{
MENDES, JÚLIA CASTRO \\ Engenheira Civil, D. Sc. \\ Universidade Federal de Ouro Preto \\ Minas Gerais; Brasil \\ jcmendes.eng@gmail.com
}

\section{RESUMO}

É de suma importância o controle de qualidade de cada etapa da construção de estruturas de concreto armado, desde o projeto à manutenção, a fim de garantir sua durabilidade. Nesse sentido, este trabalho apresenta um estudo de caso das causas e tratamentos de fissuras encontradas na laje de um edifício residencial com dois anos de utilização, na cidade de Belo Horizonte (MG). Inicialmente, foram realizados o mapeamento e caracterização das fissuras. Em seguida, foram feitos testes para verificação da segurança estrutural com auxílio de extensômetros e macaco hidráulico. A partir dos estudos realizados, constatou-se que as fissuras nas lajes nervuradas podem ter sido decorrentes de falha de projeto ou da remoção adiantada do escoramento. Dentre as opções de medidas corretivas aos danos ocorridos na estrutura, escolheuse o reforço com fibra de carbono. Apesar do alto custo desta alternativa escolhida, esta técnica de reforço causou menor impacto na estética e funcionalidade da garagem.

Palavras-chave: patologia em concreto armado, fissuras em lajes, fibra de carbono.

\section{ABSTRACT}

Quality control of each step of the construction of reinforced concrete structures from design to maintenance is of paramount importance to ensure their durability. In this sense, this paper presents a case study of the causes and treatments of cracks detected in a residential building with two years of use, in the city of Belo Horizonte (MG). Initially, mapping and characterization of the cracks were performed. Then, tests were made to verify structural safety with the aid of strain gauges and hydraulic jacks. From the studies performed, it was found that the cracks in the ribbed concrete slabs may have been due to design failure or early removal of shoring. Among the options for corrective measures for damage to the structure, carbon fiber reinforcement was chosen. Despite the high cost of this chosen alternative, this reinforcement technique had less impact on the esthetics and functionality of the garage.

Keywords: reinforced concrete pathology, plate cracks, carbon fiber. 


\section{INTRODUÇÃO}

O sistema estrutural em concreto armado é amplamente adotado pela indústria da construção civil brasileira. A escassez de áreas urbanas disponíveis para a construção tornam os edifícios de múltiplos pavimentos como uma solução tanto em âmbito residencial como comercial, principalmente para regiões metropolitanas. Com a competição mercadológica para a venda de unidades, muitas construtoras acabam por acelerar irresponsavelmente as etapas de projeto e execução (BERENGUER, RAMOS, et al., 2016).

O desenvolvimento adequado do projeto e o uso materiais de construção de qualidade são essenciais para a redução das possíveis manifestações patológicas, no entanto, não é garantia a ausência desses problemas (OLIVEIRA, ANJOS e SANTOS, 2016). Segundo Souza e Ripper (1998), o surgimento de problemas patológicos indica, de maneira geral, a existência de uma ou mais falhas durante uma das etapas da construção, que podem ser divididas basicamente em três: concepção, execução e utilização.

As fissuras estão entre as principais manifestações patológicas encontradas em construções de concreto armado, de acordo com Bertolini (2010). O aparecimento de fissuras pode levar a redução da durabilidade e, em casos extremos, indicar dano à capacidade estrutural (HELENE, 1992).

Incertezas quanto à segurança estrutural são situações que justificam uma intervenção com reforço de uma estrutura (SANTOS, NICÁCIO, et al., 2014). A escolha correta da técnica para a reabilitação estrutural é de suma importância para a resolução do problema e na recuperação da vida útil da estrutura. Deve ser levado em conta para a seleção: fator econômico, nível da degradação, possibilidade de interdição do local, interferência na arquitetura, disponibilidade de mão-de-obra e segurança dos usuários (CUNHA, CHAVES, et al., 2015).

Os principais métodos de reforço das estruturas consistem na adição de elementos estruturais à face externa das peças. $\mathrm{O}$ reforço com fibra de carbono apresenta vantagens como a alta resistência mecânica, alta rigidez do material e durabilidade, além de facilidade de instalação e acréscimo de pouca carga permanente (DUSHIMIMANA, ZIADA e TUHTA, 2018).

O controle de qualidade de cada etapa da construção, do projeto à manutenção, reduz a probabilidade de aparecimento de manifestações patológicas e, também, de preocupação, incômodos e gastos além dos previstos para os usuários. Segundo Helene (1997), os custos de intervenção estrutural crescem exponencialmente quanto mais tardia for realizada a intervenção.

Nesse cenário, o objetivo deste trabalho é apresentar as manifestações patológicas encontradas em um estudo de caso de um edifício residencial e a solução adotada para o problema encontrado, após a realização de perícia por uma equipe especializada.

\section{MATERIAIS E MÉTODOS}

O condomínio residencial estudado é composto por 3 blocos com 19 pavimentos cada, localizado na cidade de Belo Horizonte (MG). O empreendimento foi finalizado em setembro de 2013 e logo foram entregues as unidades aos proprietários. Após a ocupação, observou-se o início da formação de fissuras nas lajes nervuradas do nível subsolo. Esta manifestação causou insegurança e desconforto aos moradores, que, consequentemente, acionaram a construtora. A construtora, por sua vez, contratou uma empresa especializada em análise e projetos de intervenção de estrutura de concreto armado para avaliação in loco da condição apresentada.

O presente trabalho apresenta o acompanhamento das etapas de inspeção, teste e reparo da laje em questão. As informações foram obtidas através de documentos fornecidos pelo condomínio, como os projetos arquitetônicos e estruturais, além das vistorias realizadas pelos autores . A organização do trabalho pode ser explicada com o auxílio do fluxograma da Figura 1. 


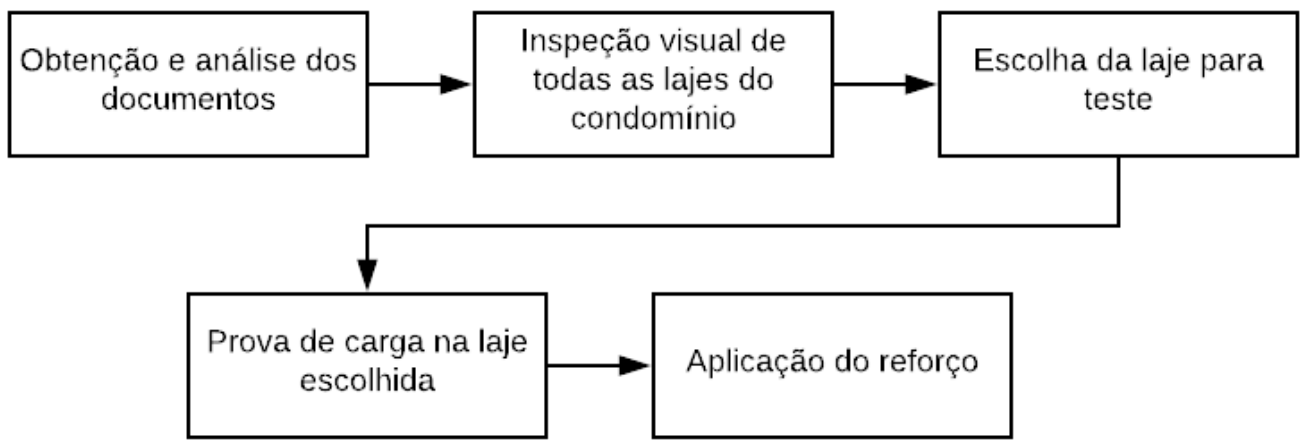

Figura 1: Fluxograma da metodologia utilizada.

Inicialmente, realizou-se a caracterização e mapeamento das fissuras, a medição da abertura de fissuras foi obtida através do fissurômetro. Após a análise da inspeção, uma laje foi escolhida para a realização da prova de carga e acompanhamento da evolução da fissura, por meio da aplicação de placas de vidro. Além disso, foram utilizados extensômetros para monitorar o comportamento das armaduras, durante o teste de carga.

Após os ensaios realizados, a equipe especializada constatou a necessidade de reforço estrutural nas lajes nervuradas de concreto armado na região do segundo subsolo do estacionamento. O reforço foi realizado com fibra de carbono.

\section{RESULTADOS E DISCUSSÕES}

Após a entrega do edifício, os ocupantes passaram a notar o surgimento de fissuras nas lajes nervuradas de concreto armado. Todas as fissuras identificadas eram transversais às vigotas da laje nervurada, conforme Figura 2. Após reclamações com a construtora, uma empresa especializada foi acionada para avaliar as condições estruturais. $O$ trabalho da empresa abrangeu desde a vistoria preliminar à aplicação do reforço estrutural mais adequado para o sistema.

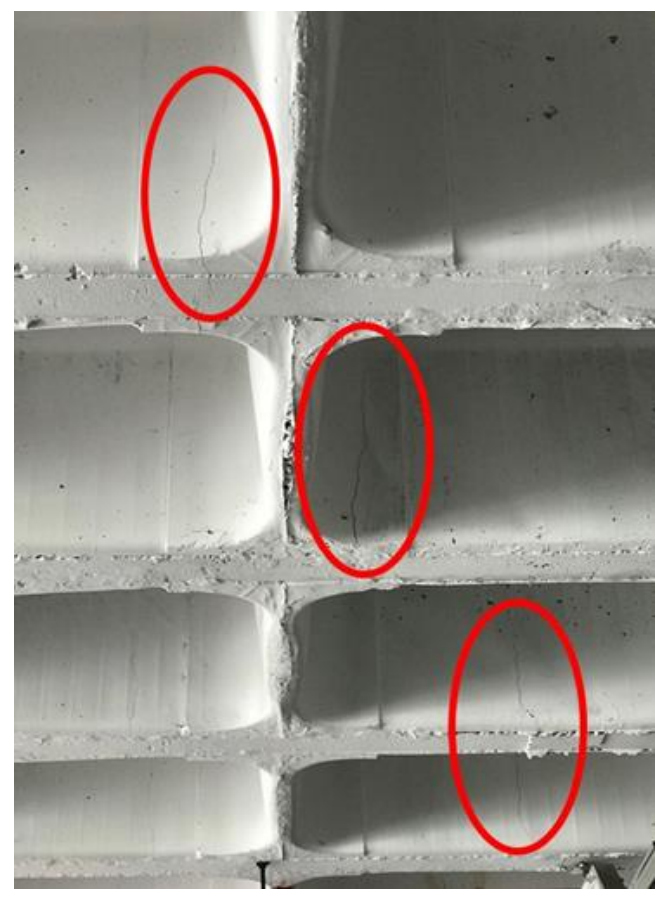

Figura 2: Fissuras detectadas na laje nervurada.

\subsection{Mapeamento e caracterização das fissuras}

As fissuras foram encontradas tanto no primeiro quando no segundo subsolo, ambos pavimentos de estacionamentos dos prédios. É apresentado um mapeamento deste problema na Figura 3. 


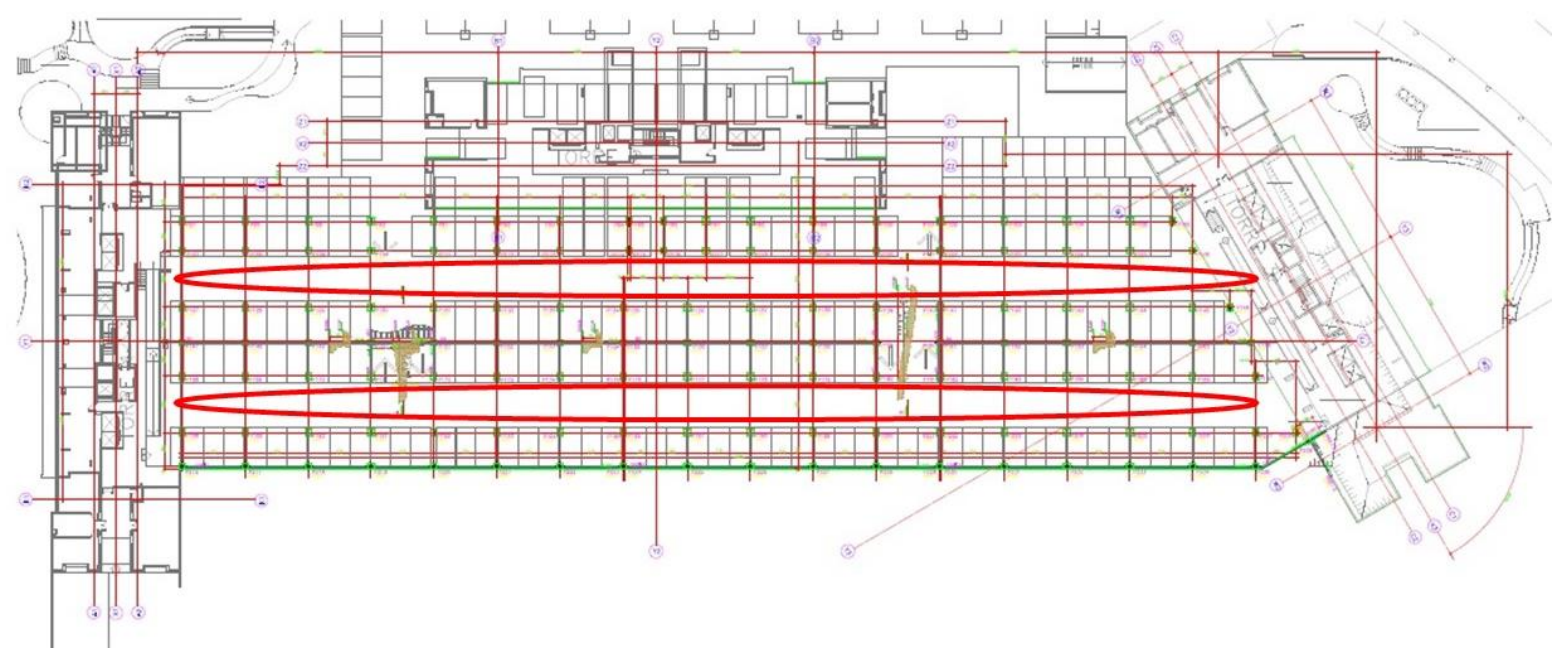

Figura 3: Mapeamento das fissuras do segundo subsolo.

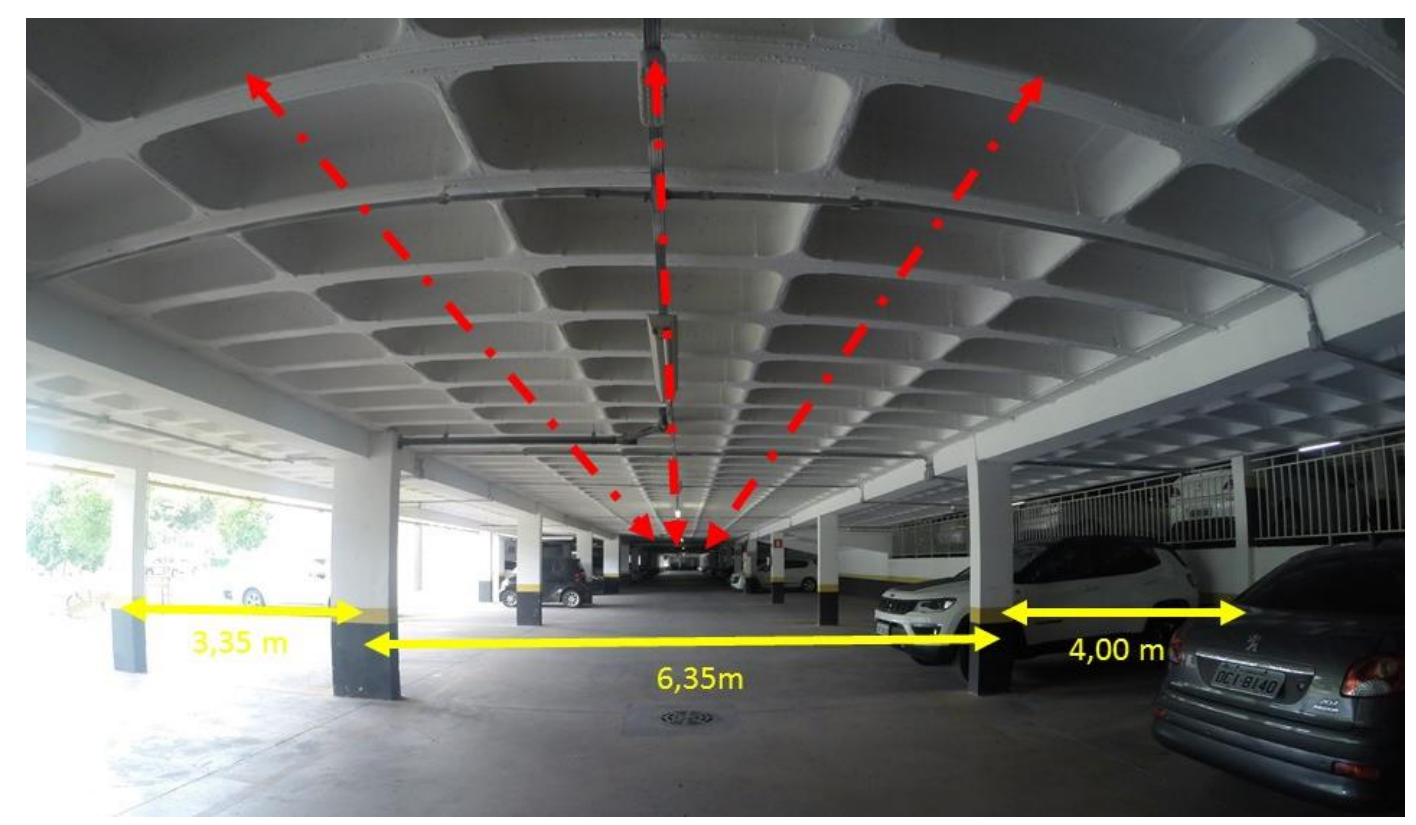

Figura 4: Região mapeada com fissuração.

As fissuras ocorreram predominantemente nos maiores vãos da estrutura, com comprimento de 6,35 m, como mostrado na Figura 4. As linhas marcadas indicam os locais de concentração das fissuras.

\subsection{Realização de testes}

Duas regiões foram as escolhidas para a realização do teste de prova de carga, uma em cada subsolo. Para isso, foi necessário a interdição das vagas de garagem desta área. Duas nervuras, escolhidas pelo engenheiro da empresa contratada, foram selecionadas para a realização do teste. Foram instalados extensômetros nestas nervuras, para monitoramento do comportamento das armaduras antes, durante e após o macaqueamento, mostrado em Figura 5. Após a aplicação do reforço, também foi realizado o monitoramento do comportamento das estruturas. 

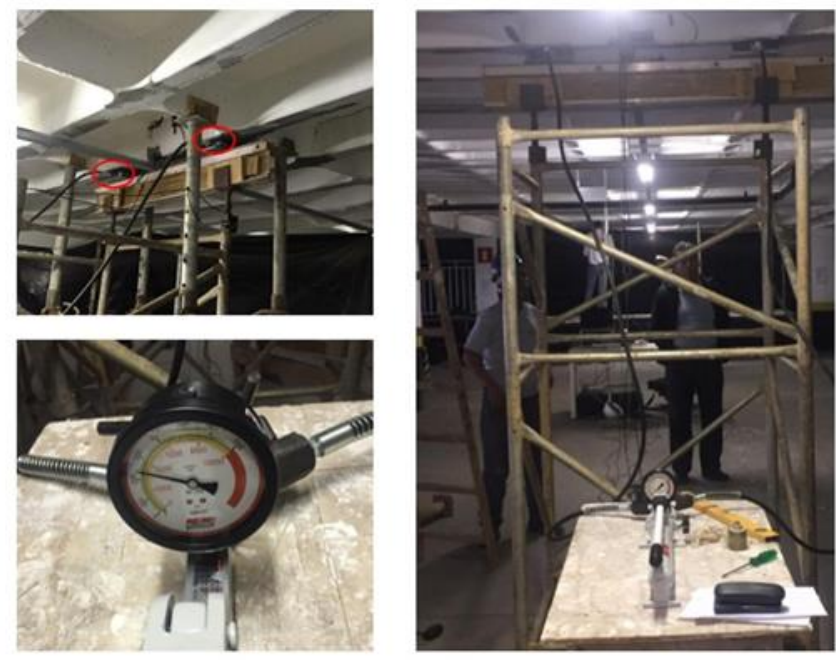

Figura 5: Instalação de extensômetros nas nervuras.

Após o macaqueamento, foi feito o escoramento da estrutura e a retirada da torre de trabalho. Os trechos onde haviam sido colocados os extensômetros foram fechados e nivelados com argamassa polimérica para que pudessem receber a fibra de carbono. Após a cura da resina para a aplicação da fibra, as escoras de apoio do sistema foram desativadas de forma controlada. Em seguida, foram realizadas provas de carga nas mesmas nervuras, para avaliar o comportamento após o reforço instalado.

A partir dos resultados obtidos, observações in loco, análise do histórico da edificação, foi constatada a necessidade de reforço em todas as nervuras da laje apenas do segundo subsolo. O método adotado para reforço destas nervuras foi a aplicação de fibra de carbono.

\subsection{Aplicação do reforço}

A aplicação da fibra de carbono foi realizada em etapas, listadas: preparação da superfície, imprimação do local, correção das imperfeições, recorte da fibra conforme tamanho especificado em projeto (Figura 6), aplicação da primeira camada de resina, aplicação da fibra e devidas aplicações de resina e fibra conforme projeto (Figura 7) e, por fim, camada de acabamento.

De acordo com o projeto do engenheiro responsável, locais mais solicitados receberam quatro camadas de fibra de carbono, enquanto o restante, três camadas. A interdição das vagas de garagem foi realizada de maneira a menor impactar os condôminos.
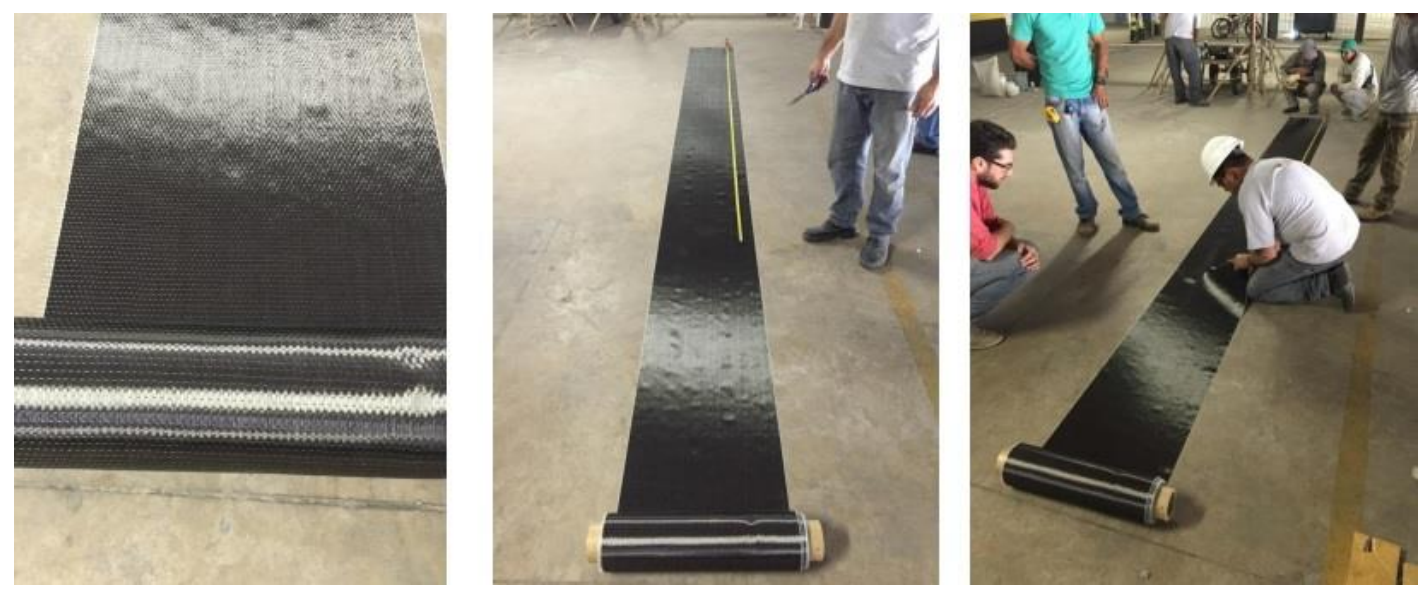

Figura 6: Recorte da fibra de carbono. 

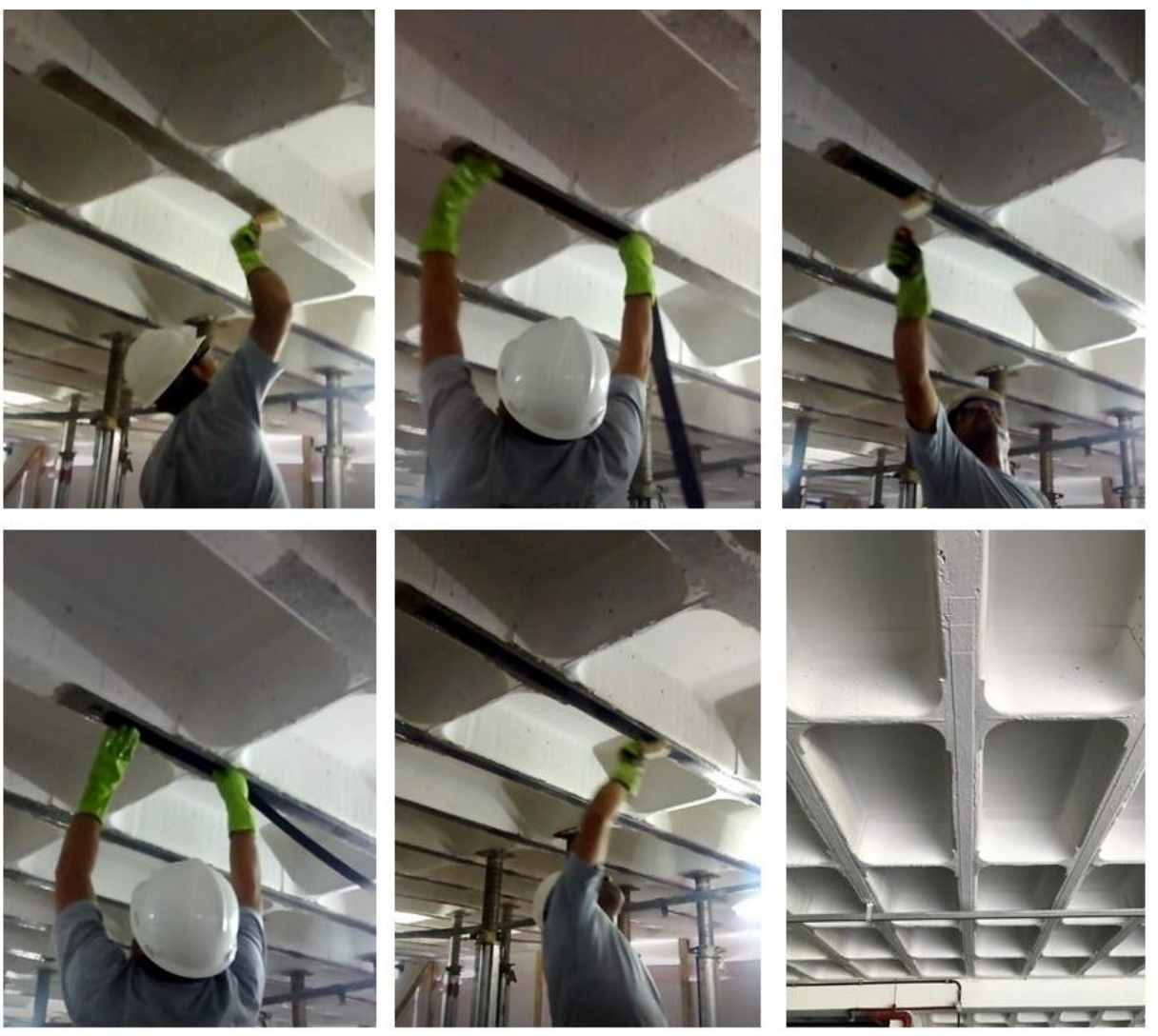

Figura 7: Aplicação do reforço.

Sabe-se que os gastos para reabilitação de estruturas nem sempre são viáveis, logo essa análise de custo é fundamental no processo de definição do reparo estrutural. Outros fatores também são levados em consideração, como a durabilidade, a possibilidade de alteração da arquitetura (para a inclusão de um pilar, por exemplo), o tempo para execução do reforço e a eficiência da técnica escolhida.

Cada projeto possui sua particularidade, apresentando restrições a determinadas alternativas de reforço, tanto do ponto de vista estrutural quanto da funcionalidade. Nesse caso, o reforço com fibra de carbono mostrou-se vantajosa devido a rápida aplicação quando comparada a outros métodos, não interferência na arquitetura local, menor necessidade de manutenção e domínio da técnica pela empresa contratada.

\section{CONCLUSÃO}

Durante a perícia, constatou-se que as fissuras foram decorrentes da sobrecarga de utilização da estrutura. O dimensionamento adequado evitaria o aparecimento dessa manifestação patológica e, consequentemente, o incômodo e gastos pós entrega da obra.

Pretendeu-se, também, avaliar o reparo feito com fibra de carbono na laje nervurada. Assim, como a manifestação patológica era de grande extensão, técnicas que comprometem a arquitetura do local e elevado tempo de execução não eram viáveis. No caso, a perda de vagas de garagem ou a interdição a longo prazo dificultava o funcionamento do estacionamento, além da frustração do proprietário que recentemente adquiriu o imóvel. Portanto, apesar do alto custo investido na técnica de reforço, a aplicação de folhas de fibra de carbono causou menor impacto aos usuários, tanto do ponto de vista do cronograma de execução da obra, como posteriormente com futuras manutenções.

O acompanhamento da perícia comprovou que esta requer muitos cuidados e uma investigação criteriosa, em alguns casos, mais complexas do que a execução de uma nova obra. Assim, o acompanhamento do desenvolvimento do projeto e da etapa de execução, minimiza a ocorrência de manifestações patológicas, além do incômodos e gastos além dos previstos para os usuários. 


\section{AGRADECIMENTOS}

O presente trabalho foi realizado com apoio da Coordenação de Aperfeiçoamento de Pessoal de Nível Superior - Brasil (CAPES) - Código de Financiamento 001. Os autores também agradecem à FAPEMIG, CNPq e UFOP pelo apoio para a realização e apresentação dessa pesquisa. Somos gratos ainda pela infraestrutura e colaboração do Grupo de Pesquisa em Resíduos Sólidos - RECICLOS - CNPq.

\section{REFERÊNCIAS}

BERENGUER, R. A. et al. Discussion on Pathological Manifestations in Reinforced Concrete Buildings and Their Relations With the Construction Process. Electronic Journal of Geotechnical Engineering, 2016. 4163-4173.

BERTOLINI, L. Materiais de Construção - Patologia, Reabilitação e Prevenção. São Paulo: Oficina de Textos, 2010. CUNHA, J. et al. Distribuição otimizada do reforço com fibras de carbono em lajes de concreto armado. Ambiente Construído, v. 15, p. 153-167, 2015.

DUSHIMIMANA, A.; ZIADA, M.; TUHTA, S. EFFECT OF CARBON FIBER REINFORCED POLYMER (CFRP) COMPOSITES APPLIED TO WALLS AND SLABS OF MASONRY BUILDING. International Journal of Advance Engineering and Research Development, v. 5, p. 2434-2442, 2018.

HELENE, P. R. L. Manual para Reparo, Reforço e Proteção de Estruturas de Concreto. São Paulo: Pini, 1992.

OLIVEIRA, J.; ANJOS, M.; SANTOS, M. Evaluation of pathological manifestations in concrete structural floor destined to the operation of vehicles in garage: case study of residential building located in the federal district.. Journal of Building Pathology and Rehabilitation, 2016. 16.

SANTOS, G. S. et al. Sistema de reforço à punção de lajes lisas de concreto armado com polímeros reforçados com fibra de carbono (PRFC). Revista IBRACON de estruturas e materiais, v. 7, p. 592-625, 2014.

SOUZA, V. C.; RIPPER, T. Patologia, Recuperação e Reforço de Estruturas de Concreto. 1. ed. São Paulo: Pini, 1998. $255 \mathrm{p}$. 